\title{
Variation among Persian Walnuts in Response to Inoculation with Xanthomonas campestris pv. juglandis
}

\author{
Keith E. Woeste and Gale H. McGranahan \\ Department of Pomology, University of California, Davis, CA 95616 \\ M.N. Schroth \\ Department of Plant Pathology, University of California, Berkeley, CA 94720 \\ Additional index words. walnut blight, Juglans regia
}

\begin{abstract}
Walnut blight of English walnut (Juglans regia L.), incited by Xanthomonas campestris pv.juglandis (Pierce) Dowson, causes significant crop loss in California. To assess levels of resistance in walnut germplasm, leaves and nuts of mature walnut genotypes were inoculated with $X$. campestris pv. juglandis. Significant differences were found among cultivars in size and frequency of lesions on leaves and in frequency of abscission of diseased leaves. Cultivars also varied in frequency of abscission of nuts following infection and in marketability of infected nuts. Afthough there was considerable variation in disease levels over 2 years, leaves of PI 159568 consistently received significantly higher disease ratings than leaves of 'Chandler' or 'Adams'. Nuts of 'Adams ', 'Payne', PI 18256, and 'Sinensis 5' abscised less frequently following inoculation than nuts of other cultivars. In addition, the quality of infected nuts that did not abscise was consistently better for PI 18256 and 'Sinensis 5'. The rank of cultivars for levels of disease in inoculated leaves was not significantly correlated with the rank of cultivars for frequency of infestation of dormant buds associated with infected foliage. The apparent resistance of walnut germplasm may be affected by the abscission or necrosis of infected tissues.
\end{abstract}

The major nut and foliage disease of Persian walnut in California is walnut blight incited by the bacterium Xanthomonas campestris pv. juglandis (Univ. of California Statewide Integrated Pest Management Project, 1982). The disease also limits walnut production in other regions of the world (Chariot and Germain, 1988; Ramos, 1985; Vavasour, 1984). All succulent tissues may be attacked (Miller and Bollen, 1946). Symptoms on leaves begin as small, water-soaked spots that can expand to form angular necrotic lesions 2 to $4 \mathrm{~mm}$ across and typically extend along veins as the disease progresses (Ark, 1944). Infected male florets become necrotic and deform the expanding catkin. Infected distillate flowers often abscise, but later infections on the hull of developing fruit expand rapidly, creating dark sunken lesions. If infection occurs before shell-hardening, the kernels are usually destroyed; infection after shell-hardening results in dark kernels and poor-quality nuts (Miller and Bollen, 1946).

The primary inoculum is bacteria that have overwintered in dormant buds (Mulrean and Schroth, 1982). The inoculum is spread by the action of wind and rain, and infection requires the presence of free water (Miller and Bollen, 1946). Thus, blight is most severe in climates with rains throughout the growing season, causing yield losses up to $80 \%$ (Chariot and Germain, 1988). In California, cultivars that leaf out and bloom after the spring rains have subsided often escape blight. For this reason, late leafing has been a high-priority trait for selection in the breeding program at the Univ. of California (Forde, 1975).

Soon after walnut blight was first described (Pierce, 1901),

Received for publication 26 Sept. 1991. Accepted for publication 13 Jan. 1992. We thank Neil Willits for advice on statistical analysis and James MacDonald for critical review of the manuscript. This study was partially funded by the Walnut Marketing Board and U.S. Dept. of Agriculture/Agricultural Research Service Specific Cooperative Agreement 58-91H2-8-131. Mention of a company name does not imply endorsement. The cost of publishing this paper was defrayed in part by the payment of page charges. Under postal regulations, this paper therefore must be hereby marked advertisement solely to indicate this fact. there were many reports of resistance to the disease (Batchelor, 1921; Ramsey, 1908; Smith, 1907, 1910, 1921, 1922; Smith et al., 1912; Ware, 1903, 1904; Wickson, 1910). Although these accounts were later discredited (Miller and Bollen, 1946; Rudolph, 1933), reports of resistant cultivars continue to appear (Adhikari et al., 1988; Gibson, 1967; Miller, 1963; Shreve, 1989; Tamponi and Donati, 1990). Purported resistance has usually been based on natural infection, and it has not been clear whether the absence of blight was due to disease escape or other forms of resistance.

The objective of this study was to determine if there is genetic variation in walnuts in response to controlled inoculation with $X$. campestris pv. juglandis.

\section{Materials and Methods}

Walnut germplasm. Genotypes used in the study represented the diversity of germplasm available in the Univ. of California, Davis, walnut collection. A range of origins, leafing dates, and reported susceptibility to blight (Table 1) was included. The leafing date falls when the average length of terminal buds is $2.5 \mathrm{~cm}$ (Forde, 1975). 'Payne', 'Sunland', and 'Serr' are considered very susceptible, whereas blight is not considered a problem on 'Hartley', 'Chandler', or 'Franquette' (Teviotdale et al., 1985). PI 159568 (Forde, 1975) and 'Howe' (Miller, 1963) are potentially resistant. Four mature trees of each genotype were used: two grafted on northern California black walnut [J. hindsii (Jeps.) Jeps.] and two on Paradox walnut (J. hindsii $\times$ J. regia) rootstock. Trees were irrigated and sprayed for pests in accordance with current horticultural practices (Ramos, 1985; Univ. of California Statewide Integrated Pest Management Project, 1982), except no effort was made to control blight during the years of the investigation.

Pathogen sources and inoculum production. Isolates of $X$. campestris pv. juglandis were recovered from dormant, healthyappearing walnut buds using the methods of Mulrean and Schroth (1981). Additional campestris pv. juglandis strains numbered 110, 117, and 124 were obtained from M.N.S. The numbered 
Table 1. Phenology and origin of walnut cultivars evaluated for response to inoculation with Xanthomonas campestris pv. juglandis.

\begin{tabular}{|c|c|c|c|c|c|c|}
\hline \multirow{2}{*}{$\begin{array}{l}\text { Species } \\
\text { and } \\
\text { cultivar }\end{array}$} & \multirow[b]{2}{*}{ Originy } & \multicolumn{2}{|c|}{ Leafing date ${ }^{z}$} & \multicolumn{2}{|c|}{ Full bloom } & \multirow{2}{*}{$\begin{array}{c}\text { Avg } \\
\text { harvest } \\
\text { date }\end{array}$} \\
\hline & & 1988 & 1989 & 1988 & 1989 & \\
\hline \multicolumn{7}{|l|}{ Juglans regia } \\
\hline PI 18256 & China & 5 Mar. & 16 Mar. & 26 Mar. & 4 Apr. & 18 Sept. \\
\hline PI 159568 & Afghanistan & 5 Mar. & 17 Mar. & 27 Mar. & 6 Apr. & $18 \mathrm{Sept}$. \\
\hline Sinensis 5 & Japan & 5 Mar. & 17 Mar. & 27 Mar. & 7 Apr. & 21 Sept. \\
\hline Payne & California & 7 Mar. & 19 Mar. & 27 Mar. & 8 Apr. & 15 Sept. \\
\hline Sunland & California & 9 Mar. & 22 Mar. & 5 Apr. & 12 Apr. & 6 Oct. \\
\hline Serr & California & 12 Mar. & 20 Mar. & 1 Apr. & 9 Apr. & 15 Sept. \\
\hline Hartley & California & 25 Mar. & 4 Apr. & 18 Apr. & 20 Apr. & 8 Oct. \\
\hline $0-13-1048$ & Afghanistan & 26 Mar. & -- & --- & --- & 23 Sept. \\
\hline Adams & Oregon & 27 Mar. & 4 Apr. & 2 Apr. & 7 Apr. & 10 Oct. \\
\hline Howe & Oregon & 27 Mar. & 4 Apr. &.- & --- & 9 Oct. \\
\hline Chandler & California & 27 Mar. & 6 Apr. & 14 Apr. & 19 Apr. & 3 Oct. \\
\hline Meylan & France & 1 Apr. & --- & -.. & --- & 26 Sept. \\
\hline Franquette & France & 7 Apr. & 13 Apr. & 26 Арr. & 1 May & 10 Oct. \\
\hline $\begin{array}{l}\text { lgians nino } \\
\text { Rawlins }\end{array}$ & California & 2 Apr. & 28 Mar. & --- & -.. & --- \\
\hline
\end{tabular}

${ }^{2}$ Leafing date falls when the average length of terminal buds is $2.5 \mathrm{~cm}$.

${ }^{y}$ Origin indicates where cultivar was originally selected or collected.

and wild-type strains were mixed by culturing them together in $100 \mathrm{ml}$ nutrient broth (Difco, Detroit, Mich.) + 2.5\% dextrose. Cultures were gently agitated with a rotary shaker for $36 \mathrm{~h}$, diluted with glycerol [30\% (v/v)], and stored as l-ml aliquots at $-81 \mathrm{C}$. These mixed strains were used for all inoculations to reduce the likelihood of observing a strain-specific response. Inoculum was quantified by standard dilution-plating and turbidimetric assays using light at $420 \mathrm{~nm}$.

Leaf inoculations. Cultivars were inoculated when the terminal leaflet of the first emerged leaves unfolded, about 1 week after the leafing date (Table 1). Three shoots on each of 20 branches randomly distributed over the lower half of the canopies of the four trees were inoculated. Shoots were gently sprayed to run off between 0700 and 1000 HR with a suspension of X. campestris pv. juglandis adjusted to $2 \times 10^{9}$ colony-forming units (cfu)/ml of deionized water and enclosed (three per bag) for $24 \mathrm{~h}$ in bags, $60 \times 90 \mathrm{~cm}$, made of white spunbonded olefin (DuPont, Wilmington, Del.). To maintain high humidity around the shoots, the interior of the bag was premoistened with deionized water and a wet sponge was placed inside. Controls (45 shoots distributed on 15 branches of four trees of each genotype) were treated similarly, except they were sprayed with water instead of inoculum. This study was repeated the following year on different branches of the same trees.

Nut inoculations. Similar techniques were used to inoculate nuts. In 1988, nuts were inoculated when their outside diameter measured 35 to $40 \mathrm{~mm}, \approx 5$ to 6 weeks after bloom; in 1989 nuts were inoculated at $7 \mathrm{~mm}$ and 10 to $15 \mathrm{~mm}, \approx 1$ to 2 weeks and 3 to 4 weeks after bloom, respectively. Typically two to four nuts per branch on 20 to 40 branches distributed over four trees per genotype were inoculated. Control nuts, typically three nuts per branch on 15 to 20 branches per cultivar, were treated at the same stage of maturity as inoculated nuts, but with deionized water only.

Disease assessment. Leaves were rated for disease 21 and 35 days after inoculation using a $\mathrm{O}$ to 5 disease severity scale based on number, size, and distribution of lesions and the number of leaflets abscised. Leaves rated 5 if they were completely necrotic or abscised. Two leaves of each shoot were rated: the most diseased leaf and the leaf that was most nearly opposite and distal to that leaf. Thus, six leaves (three shoots, two leaves per shoot) were rated on each branch.

Mesh bags were tied around fruits that remained attached to trees in mid-August. As each genotype reached its average harvest date (Table 1), the bags and nuts were collected. Nuts were hulled if necessary, air-dried in the bags for 1 week, and stored at $4 \mathrm{C}$ for 3 to 6 weeks until they were evaluated for kernel color according to the Walnut Color Chart (Dried Fruit Assn. of California, n.d.). Kernels darker than light amber were considered unmarketable.

A small subset of leaves (three per cultivar) and nuts (five per cultivar) were tested to confirm the presence of the disease. Bacteria were reisolated and identified using the methods of Mulrean and Schroth (1982), except leaf tissue was triturated instead of buds. In addition, overwintering buds from branches inoculated in 1989 ( $n=17$ to 20 per genotype) and control branches ( $n=9$ to 15$)$ were collected to determine the relationship between severity of leaf symptoms and subsequent overwintering populations of $X$. campestris pv. juglandis. Treated branches, typically bearing 15 to 40 buds, were harvested in random order over 5 weeks, placed in plastic bags, and stored at $4 \mathrm{C}$ for 1 to 3 days. Samples of four healthy-appearing buds were taken from each branch; when possible, two catkin and two vegetative/distillate buds were chosen. If four healthy-appearing buds could not be found on a branch, then buds with necrotic areas were used. Both necrotic (Miller and Bollen, 1946) and healthy-appearing dormant buds (Mulrean and Schroth, 1982) are able to support $X$. campestris pv. juglandis over winter. All four buds from each branch were triturated together in $10 \mathrm{ml}$ of $0.01 \mathrm{M}$ phosphate buffer using a mortar and pestle. After trituration, $1.0 \mathrm{ml}$ of the suspension was removed and serially diluted in sterile buffer. Aliquots of $0.1 \mathrm{ml}$ of the serially diluted suspension were spread onto a semiselective medium, incubated at room temperature for $\approx 5$ days, and quantitated using the methods of Mulrean and Schroth (1981).

Data analysis. Differences in lesion development were evaluated using a completely nested design (branch(tree(cultivar))). General Linear Models procedure of SAS (SAS Institute, Carey, 
N.C.) was used to perform analysis of variance (ANOVA) with Tukey's test for mean separations. The Kruskal-Wallis test and Spearman's coefficient of rank correlation were used to evaluate and correlate ranked treatment results. The Ryan-Einot-Gabriel-Welsch multiple F test of SAS was used for rank mean separation. Wilcoxon's rank sums with a chi-square test was used to compare cultivars for the frequency of a given rank. A chi-square test was used to determine if cultivars differed in frequency of bud infestation.

\section{Results}

Leaf inoculations. Genotype was a highly significant $(P \leq$ $0.001)$ source of variation in disease severity in both years and at both rating times, contributing between 57\% (1988, 35 days postinoculation) and $74 \%$ (1989, 35 days) of the total variation. In the first year, tree within genotype was also significant at 21 days $(P \leq 0.01)$ and 35 days $(P \leq 0.05)$. Leaves of PI 159568 consistently were given significantly higher disease ratings than other cultivars tested (Fig. 1). 'Adams' and 'Chandler' ranked lower than 'Franquette', 'Howe', 'Payne', PI 159568, 'Serr', and 'Sunland' 35 days after inoculation in 1988 and 1989, although their means were not significantly different than 'Sunland', 'Payne', and 'Serr' in 1988.

Leaf lesions appeared on all cultivars $\approx 14$ days after inoculation, and infections became increasingly severe. The severely infected leaves of PI 159568 began to abscise by 21 days after inoculation, and all of its infected leaves abscised by day 40 (observation only). There were significant differences among cultivars in the frequency of severe infections as measured by the proportion of leaves rated 5 on the 0 to 5 disease severity scale 35 days after inoculation (Table 2). 'Chandler' consistently had significantly fewer leaves rated 5 than 'Payne' or PI
159568. 'Chandler', 'Sinensis 5', PI 18256, 'Howe', and 'Adams' had fewer than the average number of leaves rated 5 in 1988 and 1989. Disease severity ratings were higher in 1989 than 1988 (Fig. 1), but the rank of cultivars remained fairly consistent at 35 days postinoculation (Spearman rank correlation coefficient $=0.73, P \leq 0.01)$. The rank correlation coefficient between the two rating times was $0.75(P \leq 0.003)$ and 0.83 $(P \leq 0.003)$ in 1988 and 1989 , respectively. Levels of natural infection on control branches did not vary significantly among cultivars $(P \leq 0.5)$, except for PI 18256 in 1989, which had significantly more infected branches. All control branches had a mean branch disease rating of less than one (data not presented).

Dormant bud samples. Cultivars had significantly $(P<0.01)$ different ratios of infested to noninfested dormant-bud samples when samples were from branches that bore inoculated leaves the previous growing season (Table 3). Cultivars were not significantly different when samples were from control branches. 'Chandler' and PI 159568 had the lowest ratios of infested to noninfested bud samples from inoculated branches, accounting for $50 \%$ of the chi-square value for difference among cultivars. 'Adams' and 'Payne' had the highest ratios, accounting for $23.5 \%$ and $12.4 \%$ of the total chi-square value, respectively. The rank of cultivars for the ratio of infested to noninfested dormant bud samples was not significantly correlated with the rank of cultivars for leaf lesion rating at any rating time.

Nut inoculations. Walnut cultivars were variable in the number of infected nuts retained until harvest and the marketability of infected nuts at harvest (Table 4). PI 18256, 'Payne', and 'Sinensis 5' retained an average of $79 \%$ of their infected nuts in 1988 and $67 \%$ in 1989. 'Sunland' and PI 159568 retained an average of $9 \%$ and $0 \%$ in the same years. 'Serr' retained $70 \%$
A

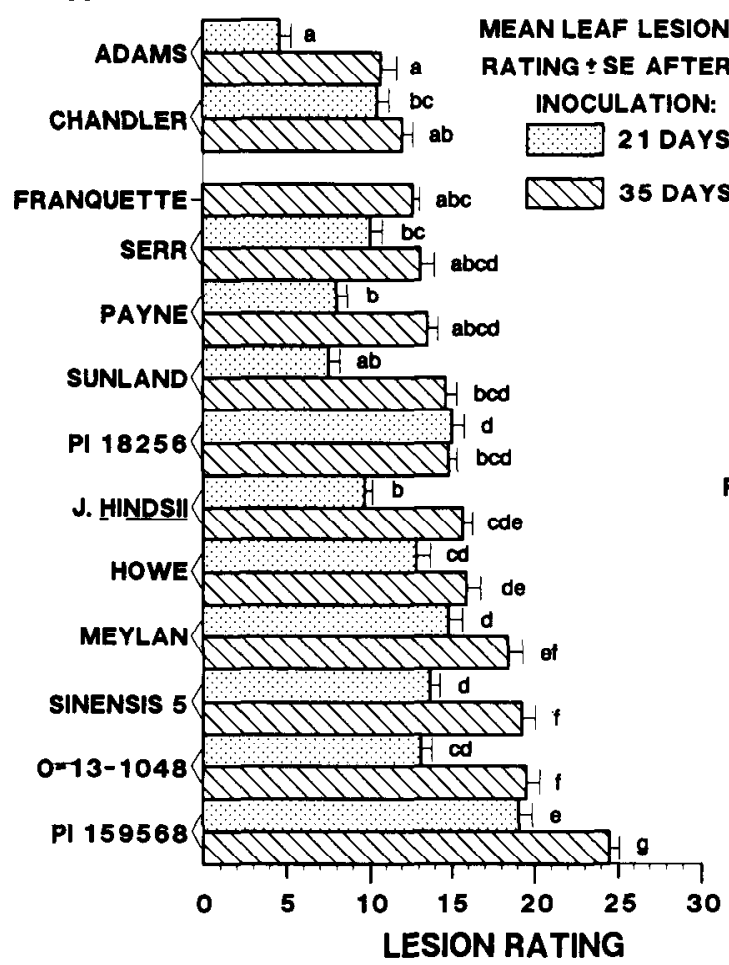

B

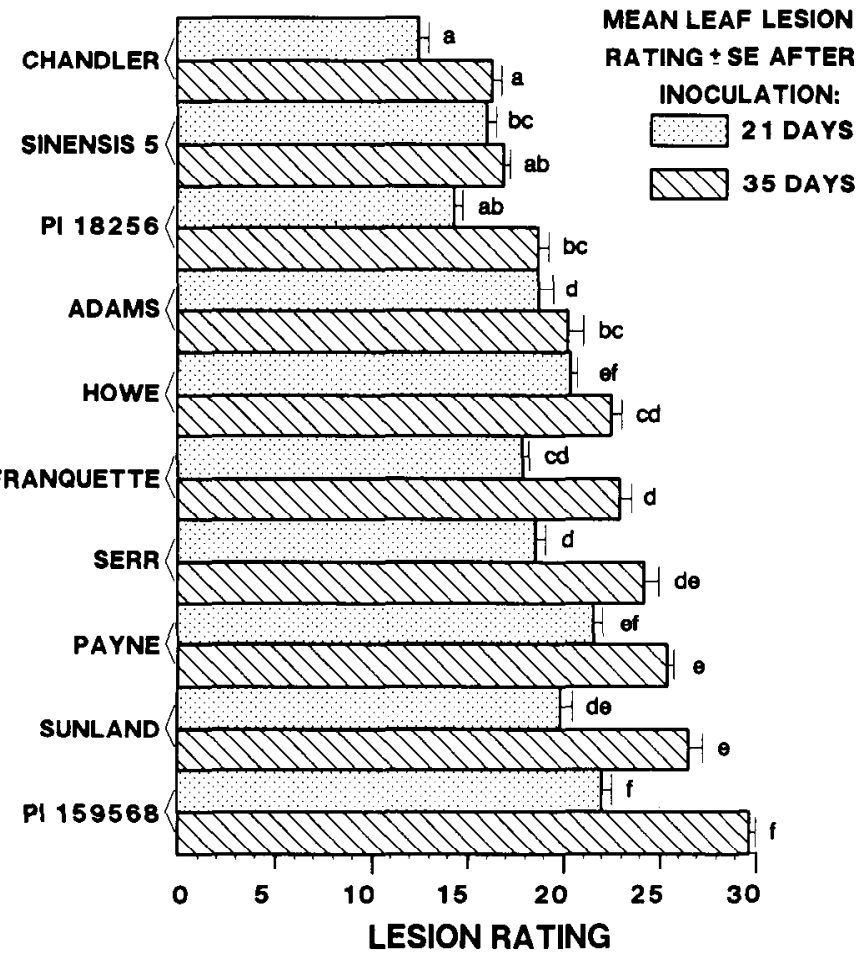

Fig. 1. Leaf lesion ratings of Persian walnut cultivars after inoculation with Xanthomonas campestris pv. juglandis. Six leaves per branch were rated using a $\mathrm{O}$ to 5 disease severity scale and these values were summed. The mean of 20 rated branches is shown for (A) 1988 and (B) 1989. Means within years and days after inoculation (21 or 35) were separated by Tukey's test $(P \leq 0.05)$. 
Table 2. Wilcoxon scores for the proportion of leaves of Persian walnut cultivars inoculated with Xanthomonas campestris pv. juglandis that became severely infected.

\begin{tabular}{lccc}
\hline \hline & \multirow{2}{*}{$\begin{array}{c}\text { No. } \\
\text { trees }\end{array}$} & \multicolumn{2}{c}{ Sum of rank scores \pm SD } \\
\cline { 2 - 4 } Cultivar & 3 & $48.0 \pm 13.4$ & 1989 \\
\hline Chandler & 4 & $80.0 \pm 15.2$ & $20.0 \pm 21.4$ \\
Sinensis 5 & 4 & $64.0 \pm 15.2$ & $38.0 \pm 21.4$ \\
PI 18256 & 4 & $64.0 \pm 15.2$ & $68.0 \pm 21.4$ \\
Howe & 4 & $64.0 \pm 15.2$ & $72.0 \pm 21.4$ \\
Adams & 4 & $64.0 \pm 15.2$ & $83.5 \pm 21.4$ \\
Franquette & 4 & $64.0 \pm 15.2$ & $106.0 \pm 21.4$ \\
Serr & 4 & $64.0 \pm 15.2$ & $127.0 \pm 21.4$ \\
Sunland & 4 & $127.0 \pm 15.2$ & $100.0 \pm 21.4$ \\
Payne & 4 & $140.0 \pm 15.2$ & $150.0 \pm 21.4$ \\
PI 159568 & &
\end{tabular}

${ }^{2}$ Wilcoxon scores (rank sums) for the proportion of the six rated leaves on each of 20 branches per cultivar that rated 5 on a 0 to 5 disease severity scale, 35 days after inoculation. For 'Chandler', the expected sum of the rank scores under the $\mathrm{H}_{\mathrm{o}}$ was 60 in 1988 and 80 in 1989; for all other cultivars these values were 80 in 1988 and 80 in 1989. In $1988, x^{2}=29.3$; probability of a larger value $=0.0006$. In $1989, x^{2}$ $=32.2$; probability of a larger value $=0.0002$.

Table 3. Influence of inoculation with Xanthomonas campestris pv. juglandis on frequency of infestation of samples' of dormant buds of Persian walnut cultivars.

\begin{tabular}{lcc}
\hline \hline & \multicolumn{2}{c}{$\begin{array}{c}\text { No. bud samples infested/ } \\
\text { no. taken }\end{array}$} \\
\cline { 2 - 3 } Cultivar & $1 / 19$ & Control \\
\hline Chandler & $3 / 18$ & $1 / 15$ \\
PI 159568 & $5 / 17$ & $1 / 9$ \\
Serr & $6 / 17$ & $3 / 13$ \\
Sinensis 5 & $7 / 18$ & $1 / 10$ \\
PI 18256 & $7 / 17$ & $1 / 13$ \\
Sunland & $9 / 20$ & $2 / 13$ \\
Howe & $10 / 17$ & $5 / 13$ \\
Franquette & $11 / 18$ & $5 / 13$ \\
Payne & $13 / 19$ & $3 / 12$ \\
Adams & & $2 / 15$ \\
\hline
\end{tabular}

${ }^{2}$ Four buds per sample.

yamples were from branches that bore inoculated or control leaves during the 1989 growing season.

in 1988 but only $15 \%$ in 1989. Over the two years of the study, an average of $48 \%$ of the infected nuts of PI 18256 and 'Sinensis 5' were marketable. 'Serr' and 'Payne' averaged $43 \%$ marketable nuts in 1988 but $1.5 \%$ in 1989. Almost all the infected nuts of 'Sunland' were unmarketable at harvest. "

\section{Discussion}

Significant differences in disease ratings and frequency of severe leaf infection were detected among cultivars of Persian walnut in response to inoculation with X. campestris pv. juglandis. There also were differences in the susceptibility of nuts with respect to amount of abscission and marketability following infection.

Only PI 18256 and 'Sinensis 5' had a consistently large percentage of marketable nuts at harvest following inoculation. These cultivars are derived from germplasm from the Far East, probably China; by contrast, most of the advanced breeding lines in California are of French provenance.

PI 159568 seemed highly susceptible; its leaves consistently received significantly higher disease severity ratings than other genotypes, and all its infected leaves and nuts abscised. This result contrasts with that of Forde (1975), who reported that PI 159568 appears blight resistant. However, PI 159568 also had a low ratio of infested to noninfested buds when dormant buds were sampled from branches that bore inoculated leaves the previous growing season (Table 3). These apparently contradictory results might be resolved if abscission and/or necrosis of severely infected tissues interrupts the disease cycle. Leaf abscission did not appear to be related to the restriction of bacteria from the vasculature of PI 159568, since shoots of PI 159568 were often killed by blight infections that began in the leaves.

The relative importance of different disease responses in relation to economically significant levels of resistance is uncertain. By abscising infected tissues, trees can partition resources to healthy leaves and nuts. Abscission of diseased tissues may also interrupt the disease cycle. Conversely, since abscised nuts cannot be sold, cultivars such as PI 18256 and 'Sinensis 5' that retain diseased but marketable nuts might prove more profitable

These results suggest there is genetic variability among Persian walnuts in response to infection by $X$. campestris pv. juglandis. Methods for evaluating walnut germplasm for resistance to blight should consider the entire disease cycle, since the severity of blight during some parts of the growing season may not be significantly correlated with subsequent overwintering populations of the pathogen.

\section{Literature Cited}

Adhikari, R. S., S.S. Ora, and S.B. Singh. 1988.Xanthomonas campestris pv. juglandis $-A$ new report from India, Current Sci. 57:728.

Ark, P.A. 1944. Pollen as a source of walnut bacterial blight infection. Phytopathology 34:330-334.

Batchelor, L. 1921. Walnut culture in California. Agr. Expt. Sta. Bul. 332.

Chariot, G. and E. Germain. 1988. Le noyer-Nouvelles techniques. Paris, Centre Technique Interprofessionnel des Fruits et Légumes.

Dried Fruit Association of California. (n.d.). Walnut color chart: For classifying walnut kernels in connection with the United States standards for grades of shelled walnuts and the United States standards for grades of walnuts in the shell. Santa Clara, Calif.

Forde, H.I. 1975. Walnuts, p. 439-455. In J. Janick and J.N. Moore (eds.). Advances in fruit breeding. Purdue Univ. Press, West Lafayette, Ind.

Gibson, M.P. 1967. The Manregian walnut. Annu. Rpt. Northern Nut Growers Assn. 58:105-109.

Miller, P. W. 1963. The 'Howe', an apparently blight-resistant Persian walnut variety. Plant Dis. Rptr. 47:686-687.

Miller, P.W. and W.B. Bollen. 1946. Walnut bacteriosis and its control. U.S. Dept. Agr., Bur. Plant Industry, Soils and Agr. Eng., Oregon State College, Corvallis. Agr. Expt. Sta. Tech. Bul. 9.

Mulrean, E.N. and M.N. Schroth. 1981. A semiselective medium for the isolation of Xanthomonas campestris pv. juglandis from walnut buds and catkins. Phytopathology 71:336-339.

Mulrean, E.N. and M.N. Schroth. 1982. Ecology of Xanthomonas campestris pv. juglandis on Persian (English) walnuts. Phytopathology 72:434-438.

Pierce, N. 1901. Walnut bacteriosis. Bet. Gazette 31:272-273.

Ramos, D. 1985. Walnut orchard management. The Regents of the Univ. of California, Div. of Agricultural and Natural Resources, Oakland, Publ. 21410.

Ramsey, H.J. 1908. The possibilities of walnut blight control by the use of immune varieties. Pacific Rural Press 75:212-213.

Rudolph, B.A. 1933. Bacteriosis (blight) of the English walnut and its control. California Agr. Expt. Sta. Bul. 564.

Shreve, L.W. 1989. Performance of English walnut varieties imported from eastern Europe and China. Rpt. Northern Nut Growers Assn. 80:63-66 
Table 4. Abscission of nuts of Persian walnut cultivars inoculated with Xanthomonas campestris pv. juglandis and the marketability of nuts at harvest.

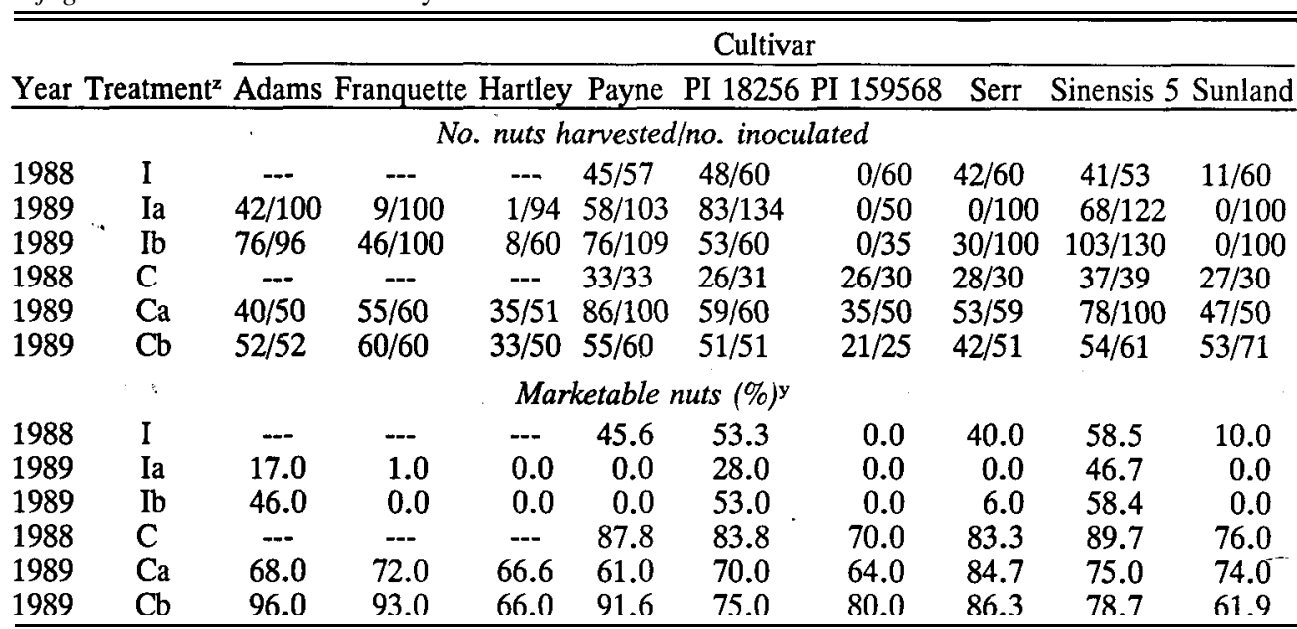

${ }^{2} \mathrm{I}=$ inoculation; $\mathrm{C}=$ control; $\mathrm{a}$ and $\mathrm{b}$ indicate size of nut at inoculation, $\approx 7$ and $15 \mathrm{~mm}$ o.d., respectively. Nuts were $\approx 35 \mathrm{~mm}$ o.d. at inoculation in 1988 .

${ }^{y}$ Expressed as percentage of all nuts inoculated.

Smith, C.O. 1921. Some studies relating to infections of and resistance to walnut blight. California Dept. Agr. Monthly Bul. 10:367-371.

Smith, C.O. 1922. Some studies relating to infections of and resistance to walnut blight, Pseudomonas juglandis. Phytopathology 12:106.

Smith, R.E. 1907. The latest on the walnut blight. Pacific Rural Press 74:309.

Smith, R.E. 1910. Walnut blight. Pacific Rural Press 79:184.

Smith, R. E., CO. Smith, and H. Ramsey. 1912. Walnut culture in California: Walnut blight. Univ. of California Agr. Expt. Sta. Bul. 231.

Tamponi, G. and G.P. Donati. 1990. Walnut cultivars susceptibility to Xanthomonas campestris. Acts Hort. 284:301.

Teviotdale, B. L., M.N. Schroth, and E.M. Mulrean. 1985. Bark, fruit and foliage diseases, p. 153-157. In: D. Ramos (cd.). Walnut orchard management. The Regents of the Univ. of California, Div. of Agricultural and Natural Resources, Oakland, Publ. 21410.

University of California Statewide Integrated Pest Management Project. 1982. Integrated pest management for walnuts. Agricultural Sciences Publications Div. of Agricultural Sciences, Berkeley, Pub]. 3270 .

Vavasour, B.J. 1984. Growing walnuts. P.D. Hasselberg, Wellington. Ware, E.G. 1903. Walnut blight. Pacific Rural Press 65:20-21.

Ware, E.G. 1904. Walnut culture and walnut blight, Pacific Rural Press 67:52.

Wickson, E.J. 1910. The walnut disease. Pacific Rural Press 79:503. 